\title{
FUZZY LOGIC BASED PERFORMANCE ANALYSIS OF VARIOUS ANTENNA STRUCTURES
}

\author{
Vardhana $\mathrm{M}^{1 *}$ \\ ${ }^{1}$ Design Engineer, NXP, India \\ ${ }^{1}$ vardhana619@gmail.com
}

\begin{abstract}
Antenna plays a very important role in the communication system. In wireless communication, the antenna is used for transmission and reception of the signal over the distance. There are so many types of antenna, which include wire antennas, traveling wave antennas reflector antenna, microstrip antennas, etc. The application of antennas depends upon the properties of the antenna and also the range of frequency of operation. Thus it is necessary to understand the behavior of the antennas at a various range of operation and choose the best antenna which fits the application. The efficiency of the antenna is determined by its performance parameters. Parameters include VSWR, Return Loss, Directivity, Bandwidth, etc. Thus the analysis of antenna is one of the main areas of concern. In this paper, we simulate various types of antennas and obtain their performance parameter such as return loss, directivity, etc. The antenna will be simulated at different frequencies using MATLAB. The analysis is very difficult when we consider all the parameters. Thus in this point of uncertainty, we employ fuzzy logic to determine the performance index of the antenna. Various antenna parameters will be input to the fuzzy inference system, which will take decision according to the set of rules. The crisp values are converted into fuzzy values by the method of fuzzification and analyzed and defuzzied to get the performance index of the antenna. Fuzzy inference system will be implemented using MATLAB and modeling of the whole system will be done in Simulink.
\end{abstract}

Keywords- Antenna Element, Fuzzy Inference System, Simulink

\section{INTRODUCTION}

The antenna is an electrical device, which is used to convert the electric power into the radio waves, thus enabling the transmission of the signal over the free space. It is also used to convert the incoming radio signals back to electrical signals. Thus antenna plays a very important role in the field of the wireless communication system. The selection of the antenna depends on various factors. These factors include the frequency of operation and also the application. The performance of the antenna is decided by the various parameters, such as Voltage Standing Wave Ratio, Reflection Coefficient, and Return Loss. These parameters vary from the antenna to antenna and also with respect to the frequency of operation. It becomes difficult to analyze the performance of the antenna with regards to these varying parameters. In this paper, we propose a new approach for the performance evaluation of antenna structures, using fuzzy logic. In this paper, the various antenna structures are simulated for the performance parameters, using MATLAB, antenna toolbox, for different frequencies. These parameters are given to the

Received: February 22, 2019

Reviewed: April 21, 2019

Accepted: April 26, 2019

* Corresponding Author 
fuzzy inference system, which evaluates the performance of the antenna, taking into consideration, all the parameters. Fuzzy inference system is developed according to the rule set derived from the knowledge of experts in the field of the antenna. The crisp values are fuzzified and analyzed for the performance using fuzzy rules and the linguistic values are defuzzified to crisp values. Analysis of the performance of the antenna is done using the proposed fuzzy inference system. The modeling of the system is done using Simulink, and performance of the antennas at various frequencies is analyzed and the performance variation of the antennas with respect to frequency is plotted.

\section{LITERATURE REVIEW}

This paper discusses the development of the system, which is used to analyze the performance of the antenna structures, using fuzzy logic. In this, the antenna structures are simulated using the MATLAB antenna design toolbox and the performance parameters are extracted. These extracted parameters are given to the analyzer to decide the performance of the antenna. In the year 1964, Lotfi A. Zadeh introduced the paper on fuzzy logic. Later in the year 1965 - 1975, Zadeh continued to broaden the fuzzy set theory. The alleviative difficulties in developing and analyzing complex systems encountered by conventional mathematical techniques led to the development of fuzzy logic. The performance analysis of the antenna structure is very complex, since the parameters that decide the performance, have to be taken into consideration at a time and have to be analyzed. In order to avoid this complexity, the fuzzy inference system has been developed in this paper. [1] discusses the application of fuzzy logic in educational institutions. It discusses how fuzzy logic can be applied to analyze the performance of students. The marks obtained by the students are the input to the fuzzy inference system which evaluates the performance of the student. Paper [2] discusses the performance evaluation of faculties in educational institutes. In this paper, we propose the development of a fuzzy inference system to evaluate the performance of the antenna. The various types of antennas are simulated using MATLAB. [3] discusses the simulation of rectangular microstrip antenna by integrating Matlab with visual basics. In [3] the rectangular microstrip antenna has been modeled and simulated. It also proposed the technique of integrating Matlab in visual basics. Matlab is a powerful tool for developing and simulating any kind of antenna structures. The tool gives the complete description regarding the performance parameters of the designed antenna. [4] Proposes the design and analysis of parabolic reflector using Matlab. In [4] the analysis of E-plane and Hplane normalized patterns are analyzed. Analysis of the parabolic reflector typically like $\mathrm{f} / \mathrm{D}$, gain, radiation patterns have been done and the corresponding results were presented. [5] Presents simulation of NxN antenna array using Matlab, and antenna array factor is plotted for each individual. It proves the result of the increasing value of directivity of the beam array factor of the antenna array, with an increase in antenna element and also analyzed the effect of the increasing antenna elements on the array factor. Design and increase of the performance of the antenna elements are discussed in [8]-[9]-[10]. Design of various antenna is available as a part of literature. Design of square patch antenna is described in [11]. Another paper describes the stacked square patch slotted broadband microstrip antenna [12]. Thus in this paper, with the help of Matlab antenna toolbox antenna structures are simulated and performance parameters are obtained. The fuzzy inference system is developed using the fuzzy logic toolbox and the modeling of the whole system is presented using Simulink.

\section{FUZZY LOGIC}

Fuzzy logic was introduced by Zadeh, in the year 1960s and 70s. Fuzzy logic embeds human knowledge into working algorithms. The computer can be programmed in such a way as to work as a human mind works. The traditional logic and set theory are all about, 
true or false, white or black, zero or one. This is not the case with fuzzy logic; it takes all the possible values.

\section{A. FUZZY SETS}

The concept of the fuzzy set is only an extension of the concept of a classical set. The fuzzy set is actually a fundamentally broader set compared with the classical set. The classical set consists of a limited number of membership such as true or false, ' 0 ' or ' 1 '. For instance, if the temperature is defined as crisp high, its range should be between 90 degrees and higher. It has nothing to do with the values less than that. But the fuzzy set will consider all the range of values. Thus the fuzzy set uses the universe of disclosure and it considers the infinite number of membership in the set.

\section{B. FUZZIFICATION AND DEFUZZIFICATION}

In order to apply the inputs to the fuzzy inference system, the values should be linguistic values. These linguistic values are represented by the degree of membership in the fuzzy set. The process of converting these crisp values into fuzzy linguistic values is called as fuzzification. Defuzzification is the process, in which quantifiable results are produced. Fuzzy inference system will output a fuzzy result, which will be described in terms of degree of membership of fuzzy sets. Defuzzification interprets the membership degrees in the fuzzy sets to specific real values.

\section{IMPLEMENTATION}

In this paper, the various antenna structures are simulated using MATLAB antenna processing tool, for different range of frequency. In order to analyze the performance of the antenna, with thee set of parameters, it becomes a tedious job. At this point of uncertainty, concept of fuzzy logic [6] is used to analyze the performance of the antennas, taking into consideration of all the parameters. The antennas [7] are simulated for frequency range from $1 \mathrm{MHz}$ to $10 \mathrm{MHz}$ and the performance parameters are analyzed using fuzzy inference system and performance index are obtained. The obtained performance index is plotted against the frequency. From the plot, it was found that, from the set of frequency under consideration, inverted $\mathrm{F}$ antenna performs better as compared with the rest of antennas considered.

\section{SIMULATION RESULTS AND DISCUSSIONS}

\section{A. ANTENNA DESIGN AND SIMULATION}

Antennas are designed and simulated using antenna design tool box in Matlab. We designed and simulated mainly five antenna structures, which are, bow tie antenna, monopole antenna, dipole antenna, inverted $\mathrm{f}$ antenna, helix antenna. Parameters such as directivity, VSWR, reflection coefficients are extracted from the simulation, which decides the performance of the antenna.

Directivity is the measure of concentration of radiation in the particular direction. It defines how directional the antenna is. Directivity and gain are differing by efficiency. Directivity can be easily estimated with the help of patterns. Directivity is the ratio of maximum radiation intensity to the average radiation intensity.

The other important parameter which decides the performance is the return loss. It is a parameter which indicates the amount of power that is lost. Hence it is a very important factor in determining the performance of antenna. VSWR and reflection coefficients are extracted from the simulation and used for further processing. 


\section{B. DEVELOPMENT OF FUZZY INFERENCE SYSTEM}

- Fuzzy decision system is developed using fuzzy logic toolbox. The input to the system is performance parameters such as, VSWR, reflection coefficient, return loss and directivity. The input crisp values are converted to fuzzy linguistic variables, by the method called as fuzzification.

- The core of the membership function for the given fuzzy set A is defined as that region of the universe that is characterized by complete and full member ship in A. which means, the core comprises those elements $\mathrm{x}$ of the universe, such that $\mu \mathrm{A}(\mathrm{x})=1$. The fuzzy set A refers to the set consisting of fuzzy linguistic variables. In this paper triangular membership functions are considered.

- Fuzzy inference system is developed using the If and Then set of rules. The rules are decided according the advice of the experts taking into consideration all the aspects of antenna performance.

- The output of the fuzzy system is the linguistic value, and has to be converted back to crisp value. This method of conversion is termed as Defuzzification. The various methods of Defuzzification include, max membership principle, centroid method, weighted average method, mean max method, center of sum, center of largest area and first(or last) of maxima. In this paper, centroid method is used for Defuzzification. Centroid method is also called as center of gravity method.

- The modeling of the whole system is done using Simulink, where the fuzzy models are imported and connections are made to implement the final model.

\section{PERFORMANCE PARAMETERS}

The antennas are simulated and performance parameters are obtained. Table I to table $1 \mathrm{~V}$ shows the value of variation of performance parameters, for bow tie antenna, dipole antenna, inverted $\mathrm{f}$ antenna, monopole antenna, and helix antenna respectively. The antennas are simulated for the frequency range from $1 \mathrm{MHz}$ to $10 \mathrm{MHz}$ and the values are given in the table below. These performance parameters are input to the fuzzy inference system and analyzed using the fuzzy rules and performance index is obtained. Table VI gives the variation of performance index of various antennas at different frequency. The plot of variation of performance index is shown in the Figure 7.

Table I. Performance Parameters of Bow Tie Antenna

\begin{tabular}{|c|c|c|c|c|c|c|c|c|c|c|}
\hline $\begin{array}{l}\text { Reflection } \\
\text { Coefficient }\end{array}$ & 0 & 0 & 0 & $-9 \mathrm{e}-9$ & $-2.2 \mathrm{e}-8$ & $-4.7 e-8$ & $-8.8 \mathrm{e}-8$ & $-1.5 \mathrm{e}-7$ & $-2.4 \mathrm{e}-7$ & $-3.6 e-7$ \\
\hline Return Loss & 0 & 0 & $3 e-9$ & $9.4 \mathrm{e}-9$ & $2.3 e-8$ & $4.8 \mathrm{e}-8$ & $8.8 \mathrm{e}-8$ & $1.5 \mathrm{e}-7$ & $2.4 \mathrm{e}-7$ & $3.7 \mathrm{e}-7$ \\
\hline VSWR & $4.7 \mathrm{e} 11$ & $3 \mathrm{e} 10$ & $5.8 \mathrm{e} 9$ & $1.85 \mathrm{e} 9$ & $7.55 \mathrm{e} 8$ & $3.64 \mathrm{e} 8$ & $1.97 \mathrm{e} 8$ & $1.15 \mathrm{e} 8$ & $7.19 \mathrm{e} 7$ & $4.7 \mathrm{e} 7$ \\
\hline Directivity & -18.7 & -24.7 & -28.2 & -30.7 & -32.7 & -34.2 & -35.6 & -36.7 & -37.8 & -38.7 \\
\hline
\end{tabular}

Table II. Performance Parameters of Dipole Antenna

\begin{tabular}{|c|c|c|c|c|c|c|c|c|c|c|}
\hline $\begin{array}{l}\text { Reflection } \\
\text { Coefficient }\end{array}$ & $-4.5 e-8$ & $-7.2 e-7$ & $-3.7 e-6$ & $-1.2 \mathrm{e}-5$ & $-2.8 e-5$ & $-5.9 e-5$ & $-1.1 \mathrm{e}-4$ & $-1.8 \mathrm{e}-4$ & $-3 e-4$ & $-4.6 e-4$ \\
\hline Return Loss & $4.5 \mathrm{e}-8$ & $7.2 \mathrm{e}-7$ & $3.7 e-6$ & $1.2 \mathrm{e}-5$ & $2.8 \mathrm{e}-5$ & $5.9 \mathrm{e}-5$ & $1.1 \mathrm{e}-4$ & $1.8 \mathrm{e}-4$ & $3 e-4$ & $4.6 \mathrm{e}-4$ \\
\hline VSWR & $3.6 \mathrm{e} 8$ & $2.4 \mathrm{e} 7$ & $4.75 \mathrm{e} 6$ & $1.5 \mathrm{e} 6$ & $6 \mathrm{e} 5$ & $2.9 \mathrm{e} 5$ & $1.5 \mathrm{e} 5$ & $9.1 \mathrm{e} 4$ & $5.7 \mathrm{e} 4$ & $3.7 \mathrm{e} 4$ \\
\hline Directivity & -18.2 & -22.9 & -24.9 & -26 & -26.5 & -26.9 & -27.2 & -31.4 & -31.7 & -31.9 \\
\hline
\end{tabular}

Table III. Performance Parameters of Inverted F Antenna

\begin{tabular}{|l|l|l|l|l|l|l|l|l|l|l|}
\hline $\begin{array}{l}\text { Reflection } \\
\text { Coefficient }\end{array}$ & $-1.9 \mathrm{e}-15$ & $-6 \mathrm{e}-14$ & $-5 \mathrm{e}-13$ & $-1.7 \mathrm{e}-12$ & $-3.9 \mathrm{e}-12$ & $-8.34 \mathrm{e}-12$ & $-1.5 \mathrm{e}-11$ & $-2.6 \mathrm{e}-11$ & $-4.2 \mathrm{e}-11$ & $-6.3 \mathrm{e}-11$ \\
\hline Return Loss & $1.9 \mathrm{e}-15$ & $6 \mathrm{e}-14$ & $5 \mathrm{e}-13$ & $1.7 \mathrm{e}-12$ & $3.9 \mathrm{e}-12$ & $8.34 \mathrm{e}-12$ & $1.5 \mathrm{e}-11$ & $2.6 \mathrm{e}-11$ & $4.2 \mathrm{e}-11$ & $6.3 \mathrm{e}-11$ \\
\hline VSWR & $9 \mathrm{e} 15$ & $2.9 \mathrm{e} 14$ & $3.5 \mathrm{e} 13$ & $1.01 \mathrm{e} 13$ & $4.45 \mathrm{e} 12$ & $2 \mathrm{e} 12$ & $1.1 \mathrm{e} 12$ & $6.6 \mathrm{e} 11$ & $4.1 \mathrm{e} 11$ & $2.7 \mathrm{e} 11$ \\
\hline Directivity & 1.74 & 1.73 & 1.73 & 1.73 & 1.73 & 1.73 & 1.73 & 1.73 & 1.73 & 1.73 \\
\hline
\end{tabular}


Table V. Performance Parameters of Monopole Antenna

\begin{tabular}{|l|l|l|l|l|l|l|l|l|l|l|}
\hline $\begin{array}{l}\text { Reflection } \\
\text { Coefficient }\end{array}$ & $-1.37 \mathrm{e}-8$ & $-2.2 \mathrm{e}-7$ & $-1.1 \mathrm{e}-6$ & $-3.5 \mathrm{e}-6$ & $-8.6 \mathrm{e}-6$ & $-1.8 \mathrm{e}-5$ & $-3.36 \mathrm{e}-5$ & $-5.8 \mathrm{e}-5$ & $-9.3 \mathrm{e}-5$ & $-1.4 \mathrm{e}-4$ \\
\hline Return Loss & $1.37 \mathrm{e}-8$ & $2.2 \mathrm{e}-7$ & $1.1 \mathrm{e}-6$ & $3.5 \mathrm{e}-6$ & $8.6 \mathrm{e}-6$ & $1.8 \mathrm{e}-5$ & $3.36 \mathrm{e}-5$ & $5.8 \mathrm{e}-5$ & $9.3 \mathrm{e}-5$ & $1.4 \mathrm{e}-4$ \\
\hline VSWR & $1.26 \mathrm{e} 9$ & $7.88 \mathrm{e} 7$ & $1.53 \mathrm{e} 7$ & $4.9 \mathrm{e} 6$ & $2 \mathrm{e} 6$ & $9.6 \mathrm{e} 5$ & $5.1 \mathrm{e} 5$ & $3 \mathrm{e} 5$ & $1.8 \mathrm{e} 5$ & $1.2 \mathrm{e} 5$ \\
\hline Directivity & -18.7 & -24.7 & -28.1 & -30.6 & -32.5 & -34 & -35.2 & -36.3 & -37.2 & -38 \\
\hline
\end{tabular}

Table V. Performance Parameters of Helix Antenna

\begin{tabular}{|l|l|l|l|l|l|l|l|l|l|l|}
\hline $\begin{array}{l}\text { Reflection } \\
\text { Coefficient }\end{array}$ & $-1 \mathrm{e}-11$ & $-1.6 \mathrm{e}-10$ & $-8.5 \mathrm{e}-10$ & $-2.6 \mathrm{e}-9$ & $-6.5 \mathrm{e}-9$ & $-1.4 \mathrm{e}-8$ & $-2.5 \mathrm{e}-8$ & $-4.3 \mathrm{e}-8$ & $-6.9 \mathrm{e}-8$ & $-1.05 \mathrm{e}-7$ \\
\hline Return Loss & $1 \mathrm{e}-11$ & $1.6 \mathrm{e}-10$ & $8.5 \mathrm{e}-10$ & $2.6 \mathrm{e}-9$ & $6.5 \mathrm{e}-9$ & $1.4 \mathrm{e}-8$ & $2.5 \mathrm{e}-8$ & $4.3 \mathrm{e}-8$ & $6.9 \mathrm{e}-8$ & $1.05 \mathrm{e}-7$ \\
\hline VSWR & $1.6 \mathrm{e} 12$ & $1 \mathrm{e} 11$ & $2 \mathrm{e} 10$ & $3.4 \mathrm{e} 9$ & $2.6 \mathrm{e} 9$ & $1.3 \mathrm{e} 9$ & $6.8 \mathrm{e} 8$ & $4 \mathrm{e} 8$ & $2.5 \mathrm{e} 8$ & $1.6 \mathrm{e} 8$ \\
\hline Directivity & -18.4 & -23.8 & -26.4 & -27.8 & -28.7 & -29.3 & -29.7 & -30 & -30.2 & -30.3 \\
\hline
\end{tabular}

Table VI. Performance IndexC of Various Antenna at Different Frequency

\begin{tabular}{|l|l|l|l|l|l|l|l|l|l|l|}
\hline Bow Tie & 0.43032 & 0.430105 & 0.49982 & 0.4499817 & 0.4998660 & 0.499674 & 0.499878 & 0.49988 & 0.49988 & 0.49988 \\
\hline Dipole & 0.500115 & 0.49988 & 0.49987 & 0.499865 & 0.499858 & 0.499851 & 0.499846 & 0.499837 & 0.499843 & 0.499847 \\
\hline Invertedf & 0.500385 & 0.585188 & 0.585288 & 0.58529 & 0.585296 & 0.585295 & 0.585295 & 0.585295 & 0.585295 & 0.585295 \\
\hline Monopole & 0.500042 & 0.499877 & 0.499824 & 0.499814 & 0.499857 & 0.49987 & 0.499878 & 0.49988 & 0.49981 & 0.49969 \\
\hline Helix & 0.500856 & 0.4998837 & 0.499659 & 0.4996323 & 0.499804 & 0.4997788 & 0.49977 & 0.499792 & 0.499802 & 0.499804 \\
\hline
\end{tabular}

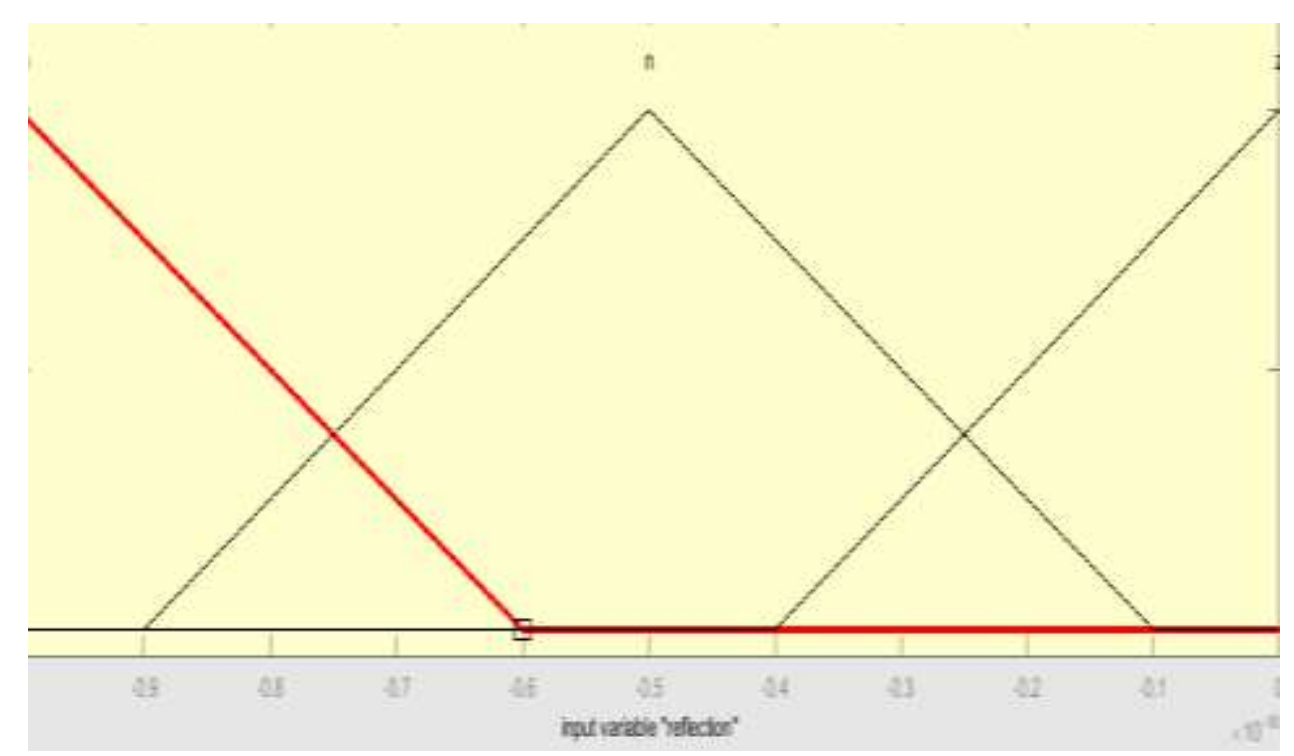

Fig. 1. Memebership Function of the Input Variable 


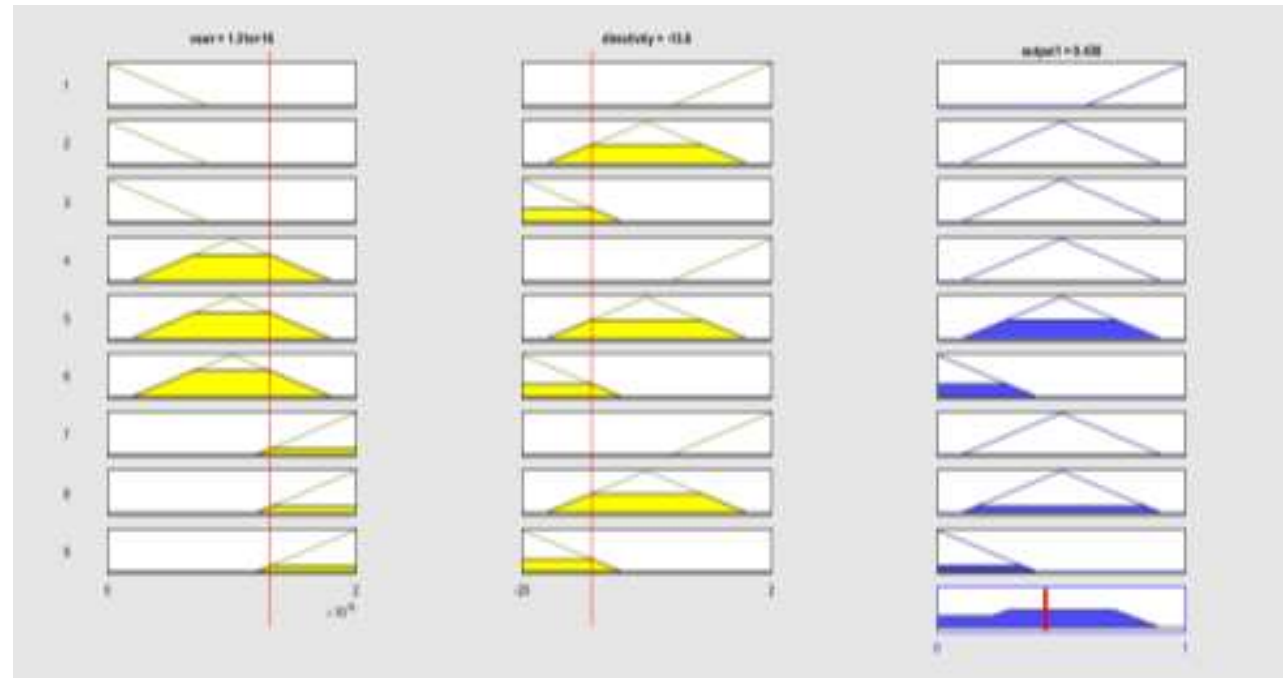

Fig. 2. Fuzzy Rule Viewer for Input VSWr and Directivity

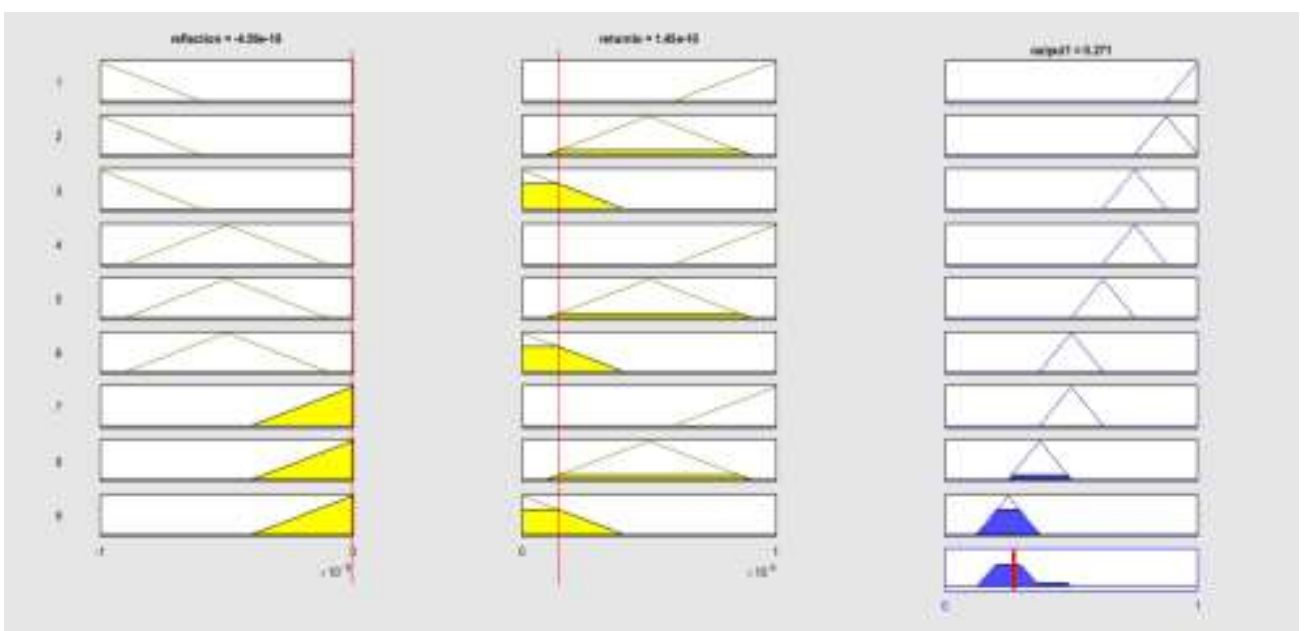

Fig. 3. Fuzzy Rule Viewer for Inputs Reflection Coefficient and Return Loss

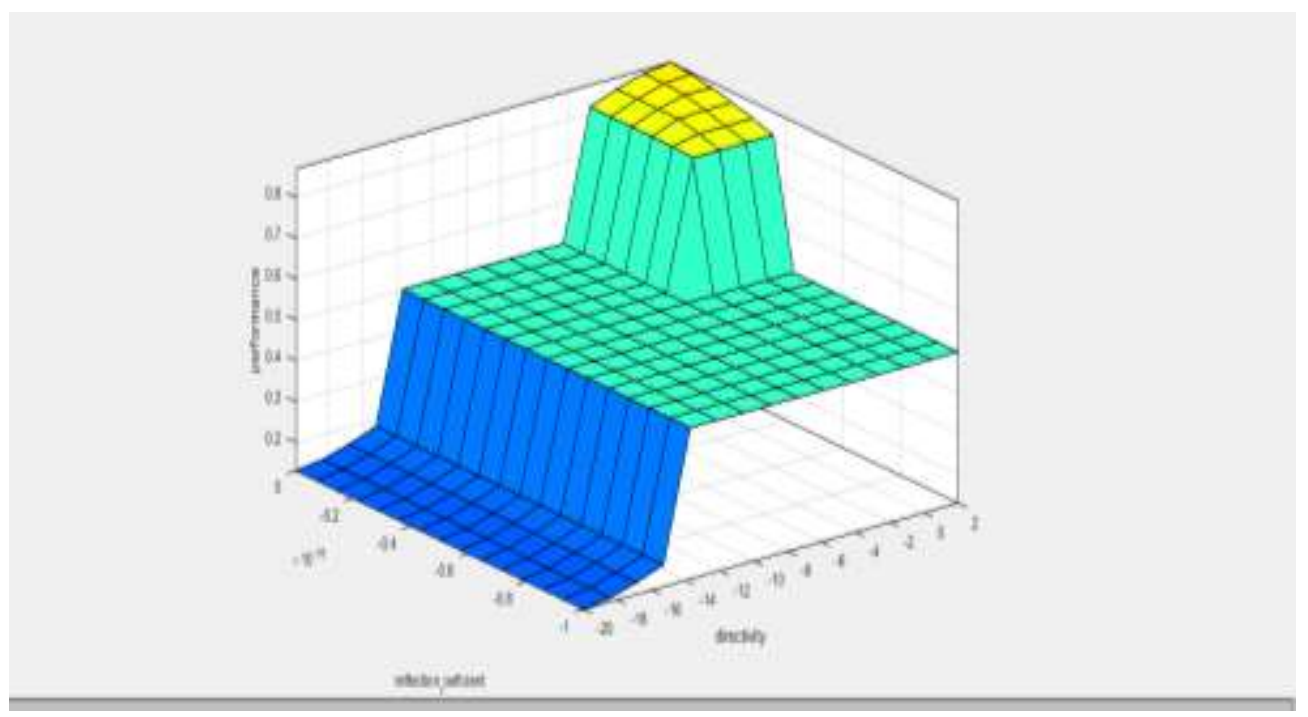

Fig. 4. Fuzzy Surface Viewer Showing the Variation of Performanc Eindex with Respect to Inputs 
Figure 1 shows the membership function for the input reflection coefficient. The fuzzy set include the variables, more negative(mn), negative(n) and zero(z), as shown in the figure. Figure 2 and figure 3 shows the rule viewer for the set of inputs. Figure 4 shows the surface view of variation of the performance index with respect to the input parameters.

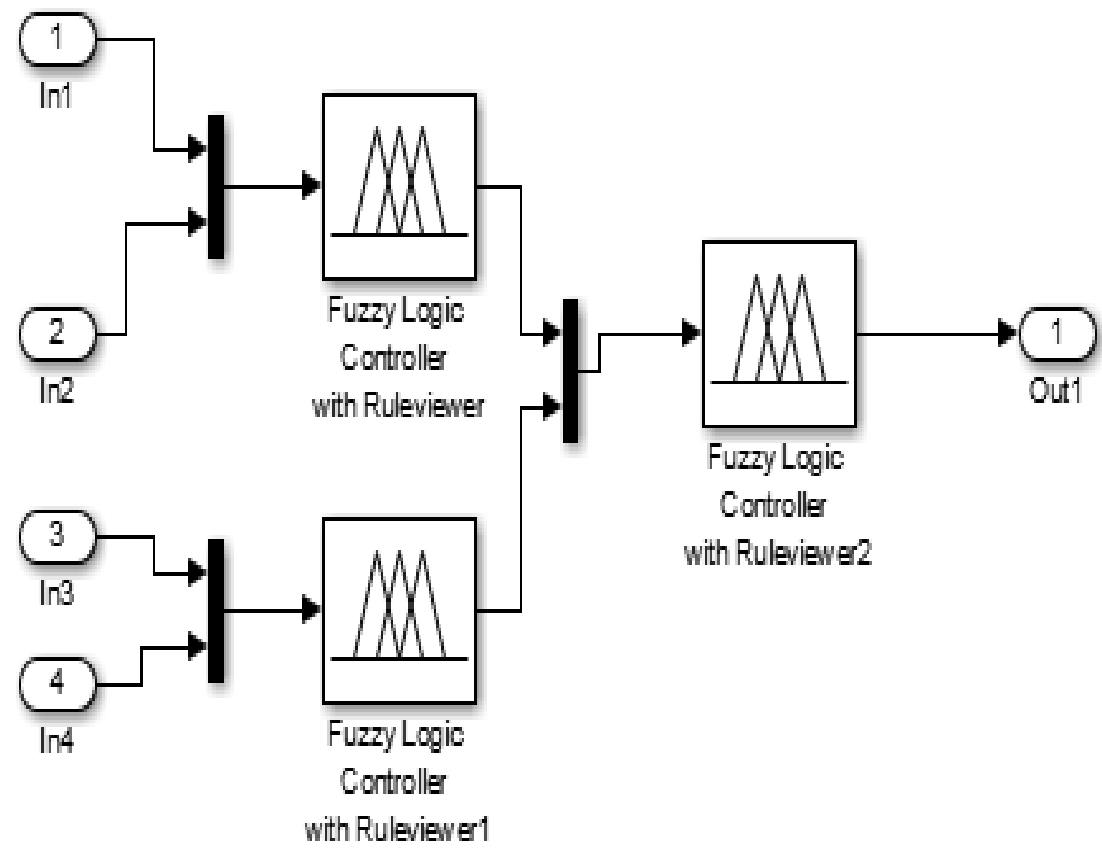

Fig. 5. Simulink model for fuzzy system

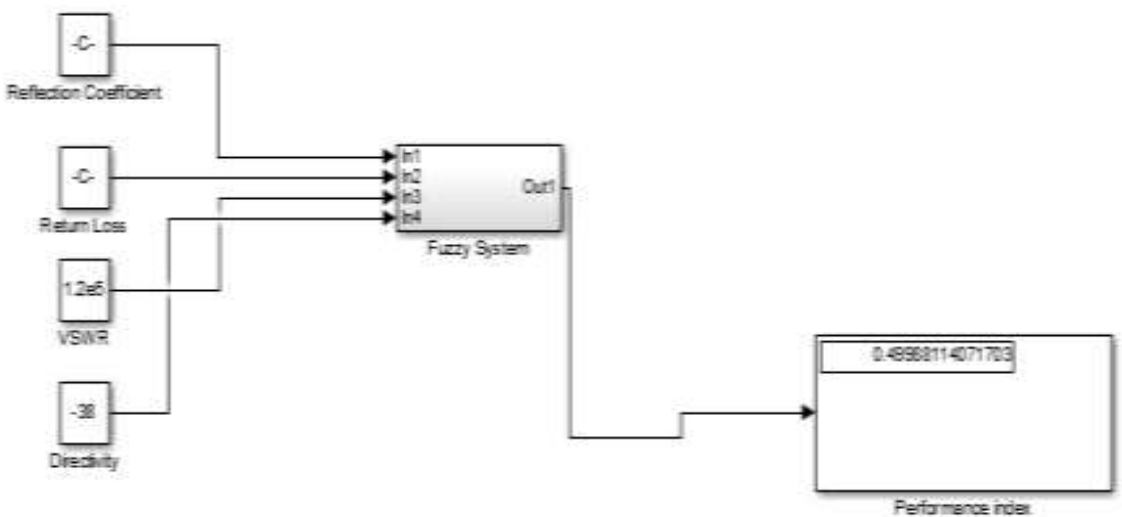

Fig. 6. Modelling of the proposed system using simulink

The developed fuzzy system is exported to simulink and fuzzy modeling is done, which is presented in the Figure 5. Figure 6 shows the modeling of the proposed system. 


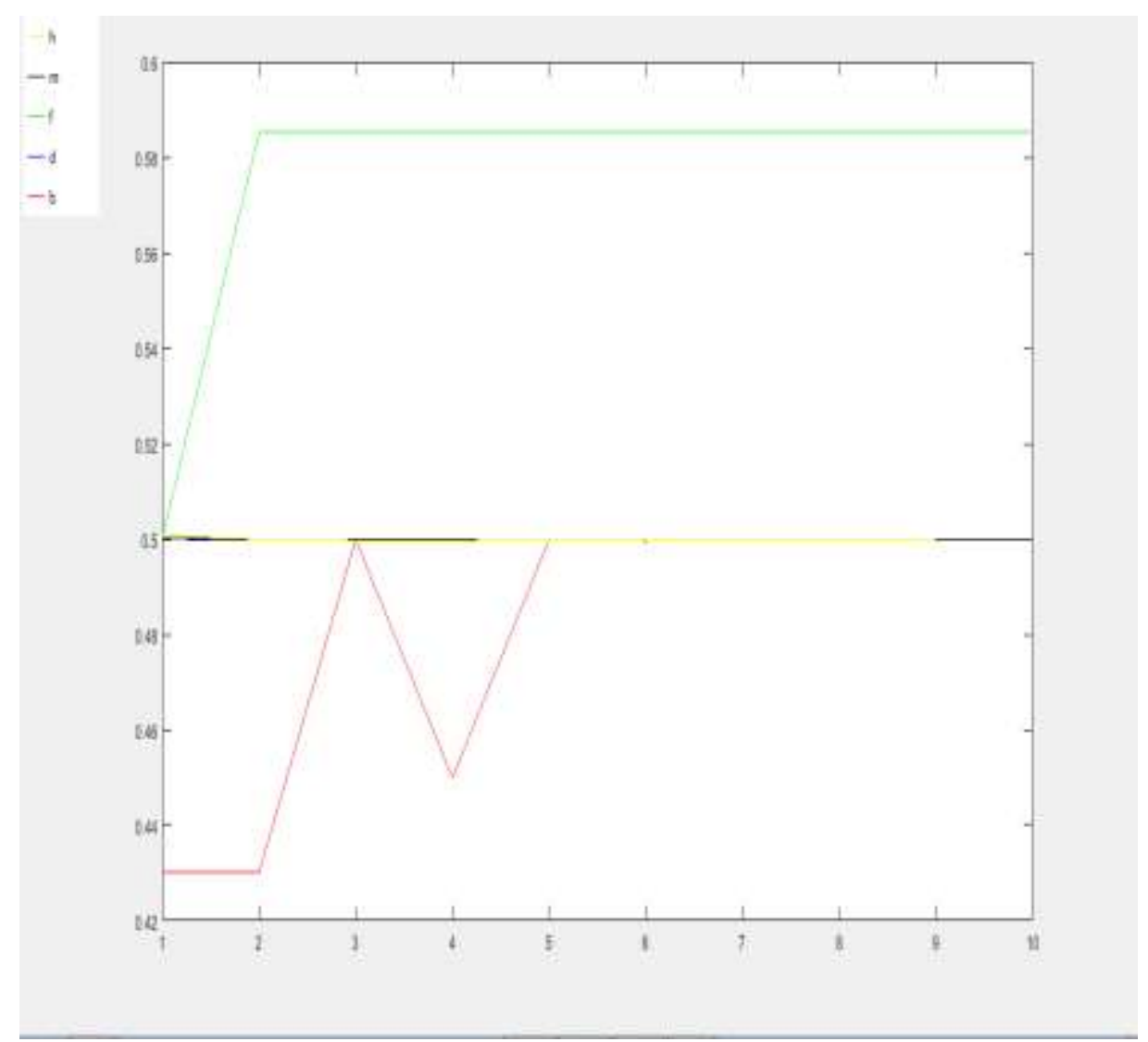

Fig. 7. Variation of performance index with respect to frequency

The performance index is plotted against the frequencies and variation is observed. Figure 7 show the variation of the performance index with respect to frequency.

\section{CONCLUSION}

In this paper, various antenna structures are simulated using Matlab and performance parameters are extracted from the simulation results. The antennas are simulated for frequency ranges from $1 \mathrm{MHz}$ to $10 \mathrm{MHz}$. This paper proposes a new concept to evaluate the performance of the antenna, based on the fuzzy logic. The conventional mathematical model for decision making cannot be applied to complex system as in the case of antenna performance. Thus this paper reduces this problem and the exact evaluation of the performance of the antenna can be done. The fuzzy system is developed and modeling of the proposed system is done using Simulink. The inputs are given to the developed system and the output is observed. The performance index of the antennas, thus obtained is plotted. From the analysis it is observed that the inverted $\mathrm{f}$ antenna performs better than the rest of the antennas considered in the frequency range $1 \mathrm{MHz}$ to $10 \mathrm{MHz}$.

\section{REFERENCES}

[1] Neetesh Saxena1, Kajal Kaushal Saxena1, "Fuzzy Logic Based Students Performance Analysis Model for Educational Institutions", VIVECHAN International Journal of Research, Vol.1, 2010

[2] Ms. G. Jyothi et al, "Fuzzy Expert Model for Evaluation of Faculty Performance in Technical Educational Institutions", Int. Journal of Engineering Research and Applications, Vol. 4, Issue 5, pp.4150, May 2014

[3] Hussain Falih Mahdi, "Simulation Of Rectangular Microstrip Antenna By Integrating Matlab In Visual Basic", Diyala Journal of Engineering Sciences, Vol. 03 , No. 01, pp. 16-24 , June 2010

[4] Kirti Chaurasiya , Satish Kumar, "Design and Analysis of Parabolic Reflector Using MATLAB", IJAREEIE, Vol. 4, Issue 3, March 2015 
[5] P. Sai Vinay Kumar, Dr M. Padmaja, "N $\times N$ Antenna Array Simulations Using MATLAB", International Journal Of Innovative Research In Electrical, Electronics, Instrumentation And Control Engineering Vol. 3, Issue 5, May 2015

[6] Daniel Ramot, Menahem Friedman, Gideon Langholz, and Abraham Kandel, "Complex Fuzzy Logic," IEEE Transactions on Fuzzy Systems,Vol. 11, No. 4, pp 450-461, August 2003.

[7] Constantine A. Balanis, "Antenna Theory Analysis and Design”, Third Edition, 2005 by John Wiley \& Sons.

[8] M. Abbak and I. Tekin, "Rfid coverage extension using microstrip-patch antenna array [wireless corner]," Antennas and Propagation Magazine, IEEE, vol. 51, no. 1, pp. 185-191, 2009.

[9] A. A. Lotfi Neyestanak, F. Hojjat Kashani, and K. Barkeshli, "E Shaped Patch Antenna Design Based on Genetic Algorithm Using Decision Fuzzy Rules", IJECE, vol. 4, no. 1, pp. 18-24, 2005.

[10] Jui-Han Lu, "Bandwidth Enhancement Design of Single-Layer Slotted Circular Microstrip Antennas", IEEE Tran. Antennas and Propagation, vol. 51, no. 5, May 2003.

[11] Amritesh K shetrimayum, Milan Singh, "Design of Square Patch Microstrip Antenna for Circular Polarization Using IE3D Software"

[12] P.K.Singhal, BhawanaDhaniram, and Smita Banerjee, "A Stacked Square Patch Slotted Broadband Microstrip Antenna", Journals of Microwaves and Optoelectronics, Vol. 3, No.2, August 2003. 
International Journal of Grid and Distributed Computing Vol. 12, No. 1 (2019) 